\title{
Related factors to human toxocariasis in a rural community of Argentina
}

\author{
Paula Chiodo, Juan Basualdo+ , Laura Ciarmela, Betina Pezzani, María Apezteguía, \\ Marta Minvielle
}

Cátedra de Microbiología y Parasitología, Facultad de Ciencias Médicas, Universidad Nacional de La Plata, Calle 60 y 120 s/n,

(1900), La Plata, Argentina

The objective of this study was to evaluate the relationship between toxocariasis frequency and demographic, environmental, sanitary variables, eosinophylia, and other intestinal parasites in a rural population of Argentina. Serological examination of 100 individuals was carried out by using ELISA technique for the detection of antitoxocara antibodies. Eosinophiles in peripheral blood, presence of intestinal parasites, and demographic, environmental, and socio-cultural data were evaluated. Eighty-one feces samples of dogs belonging to the studied people were analyzed to detect eggs of Toxocara canis. Thirty of them were from 30 dogs and 51 were pools from dog feces. Samples of dirt from around the homes ( $n: 47)$ and from public park ( $n: 4)$ were taken. To determine the associations, the $\chi^{2}$ and Fisher tests were used. The seroprevalence was 23\%. Eosinophilia in peripheral blood was detected in $86.95 \%$ seropositive individuals and in $37.66 \%$ seronegative individuals $(\mathrm{p}<0.001$, OR $=11.03)$. Of the 23 people with positive serology, $69.56 \%$ had at least one intestinal parasite. All individuals with positive serology had dogs in their homes. Among the dog owners there was a significant association between the presence of anti-toxocara antibodies and home flooding. Eggs of T. canis were detected in the feces of 5/81 dogs and three of these dogs belonged to individuals with positive serology. Eggs of Toxocara spp. were found in $41.17 \%$ of the dirt samples, eight of which came from the area surrounding the homes of individuals with positive serology $(\mathrm{p}=0.032 ; O R=$ 4.36). Taking into account all the variables influencing the frequency of toxocariasis in this population, the implementation of Public Health programs specifically focused on anti-parasitic treatment of dogs is recommended.

Key words: toxocariasis - frequency - dogs - soil - Argentina

Toxocariasis is considered a parasitosis of wide geographic distribution occurring both in developed countries and in countries with deficient sanitary, cultural, and social structures (Despommier 2003).

With the development of the ELISA technique based on the detection of antibodies anti-excretory-secretor antigens (E/S Ag), seroprevalence studies have been possible (De Savigny et al. 1979, Minvielle et al. 2000).

Frequently, the human infection with Toxocara canis larvae shows no clinical manifestations and evolves in an asymptomatic way. However, in some cases it can cause severe alterations such as fever, hepatomegaly, splenomegaly, respiratory symptoms, muscular pain, and anorexia, accompanied by high eosinophilia and high anti-toxocara titres. It can appear together with ocular disturbance, probably as a result of a low parasitic charge, as indicated by the low antibody titres and low eosinophilia accompanying these profiles (Anaruma Filho et al. 2003).

Seropositivity has been reported in the world ranging from $1 \%$ in children in Madrid (Guerra et al. 1995) to $86 \%$

Financial support: Agencia Nacional de Promoción Científica y Tecnológica (PICT 05-08245), Fundación Roemmers, Universidad Nacional de La Plata

+Corresponding author: jabasua@ atlas.med.unlp.edu.ar Received 16 January 2006

Accepted 3 May 2006 in rural children in the Caribbean (Thompson et al. 1986). Studies carried out in Latin America reveal a prevalence of $23.9 \%$ in Brazil (Anaruma Filho et al. 2003) and $9.72 \%$ in Venezuela (García-Pedrique et al. 2004).

In Argentina there have been varying seroprevalences: Taranto et al. (2003), for example, found $22.1 \%$ in aborigines from the north of the province of Salta, and Radman et al. (2000) reported a $39 \%$ in children attending clinics and hospitals.

In the epidemiology of this parasitosis, the ingestion of contaminated dirt from public parks is an important risk factor, though other transmission routes must be considered. A strong association between the presence of dogs and toxocariasis has been proposed, with diverse criteria regarding the real role of the contact with the dog in the transmission of this parasitosis (Wolfe \& Wright 2003, Habluetzel et al. 2003).

The objective of this study was to evaluate the relationship between toxocariasis seroprevalence and demographic, environmental, sanitary variables, eosinophylia, and other intestinal parasites in General Mansilla, province of Buenos Aires, Argentina.

\section{MATERIALS AND METHODS}

The area of study, General Mansilla, is located in the north east of the Province of Buenos Aires, $95 \mathrm{~km}$ from the City of Buenos Aires, Capital of Argentina. It has a population estimated in 6000 people, over $1,075.5 \mathrm{~km}^{2}$, of rural characteristics and with mainly agricultural and cattlebreeding activity, with a population density of six inhabitants per $\mathrm{km}^{2}$. 
A hundred people with or without symptoms attending the Health Center of the town over the month of November of 2004 were studied. These persons go to this Center because of different motives: vaccination, pregnancy control, pediatrics control, and several clinics syndromes. All of volunteer participants signed their consent to be performed this study. The blood samples were taken by vein puncture for the detection of anti-toxocara antibodies. Serological examination was carried out at the Parasitology Laboratory, Microbiology and Parasitology Department, School of Medical Sciences, Universidad Nacional de La Plata, by using LMD kits (Alexon-Trend, Apogent Company, US) by ELISA technique (specificity: 98\%; sensitivity: $86 \%$ ).

At the same time, each individual was performed a blood smear to evaluate eosinophiles in peripheral blood, and a serial coproparasitologic study, processed by modified Telemann technique (Gamboa et al. 2003).

Each individual was orally interviewed to register the following data: (a) age and gender; (b) presence or absence of dogs within the home; (c) house construction and design: building material, floor quality, bathroom facilities, mode excrement disposal and water supply; (d) flooding of the homes.

At the same time, 81 feces samples of dogs belonging to the studied people were analyzed coproparasitologically. Thirty of them were from $30 \mathrm{dogs}$ and 51 were pools from dog feces which lived in the same home because in the rural area is common to have more than one dog. They were processed by the modified Telemann technique and afterwards observed by optical microscope for the detection of $T$. canis eggs.

Dirt samples were taken from the ground of the interviewees homes (n: 47) and from the only public park (n: 4). The samples were processed by the Kozakos technique (1983) to detect the contamination of the soil by this geohelminth.

To determine significant associations, the $\chi^{2}$ and Fisher tests were used. The SPSS (Statistical Programme Social Science) Software version 11.5 was used.

\section{RESULTS}

The frequency of toxocariasis was $23 \%$ (23/100). The distribution by sex and age is presented in Table I. No statistically significant differences were registered.

Eosinophilia in peripheral blood $(\geq 5 \%)$ was detected in 49\% (49/100) of the population studied, 20/23 (86.95\%) of whom were seropositive for toxocariasis and 29/77 $(37.66 \%)$ were seronegative $(p<0.001$; OR $=11.03)$.

The coproparasitologic analysis revealed a frequency of 60\% (60/100): Blastocystis hominis (39\%), Giardia lamblia (14\%), and Ascaris lumbricoides (11\%) were the most frequent. Of the 23 people with positive serology, $69.56 \%$ had also at least one intestinal parasite.

Among the people with positive anti-toxocara, 26.09\% (6/23) had G. lamblia in their feces, $52.17 \%$ (12/23) had B. hominis, and $8.69 \%(2 / 23)$ had A. lumbricoides. The people parasited with $A$. lumbricoides had associated eosinophilia $(p=0.021$; OR $=5.51)$. The presence of one, two or three intestinal parasites prevalent in the studied individuals are observed in Table II. It can be observed in this
TABLE I

Seroprevalence of toxocariasis in 100 people from General Mansilla, Argentina. Sex and age distribution

\begin{tabular}{lccrrr}
\hline & & $\begin{array}{c}\text { Number of } \\
\text { people }\end{array}$ & \multicolumn{2}{c}{ Seropositives } \\
\cline { 4 - 5 } Sex & Age range & examined & $\mathrm{N}$ & $\%$ \\
\hline Females & $\leq 14$ years old & 34 & 7 & 20.6 \\
\multirow{3}{*}{ Males } & $>14$ years old & 20 & 4 & 20.0 \\
& $\leq 14$ years old & 38 & 10 & 26.3 \\
& $>14$ years old & 8 & 2 & 25.0 \\
\hline
\end{tabular}

TABLE II

Association between seroprevalence of toxocariasis and the presence of prevalent intestinal parasites in 100 people from General Mansilla, Argentina

\begin{tabular}{lcccccc}
\hline & \multicolumn{2}{c}{ Serology (-) } & & \multicolumn{2}{c}{ Serology (+) } \\
\cline { 2 - 3 } \cline { 6 - 7 } Prevalent parasites & $\mathrm{N}$ & $\%$ & & $\mathrm{~N}$ & $\%$ \\
\hline Absence & 41 & 83.7 & & 8 & 16.3 \\
Presence of 1 & 31 & 77.5 & & 9 & 22.5 \\
Presence of 2 & 5 & 55.6 & & 4 & 44.4 \\
Presence of 3 & 0 & 0 & & 2 & 100
\end{tabular}

Prevalent parasites: Blastocystis hominis, Giardia lamblia, Ascaris lumbricoides.

Table that the prevalence of toxocariasis increases with the presence of one, two or three prevalent parasites ( $p=$ $0.016)$. The test for linear association is still more significant $(p=0.007)$.

Table III shows the environmental and socio-cultural data collected in the survey and their distribution among the individuals with positive serology. Most of the people living in good sanitary conditions $(43.5 \%)$ had dogs in their homes $(p=0.013)$.

The statistical analysis showed a significant association among the dog owners $(n=81)$ between the presence of anti-toxocara antibodies ( $\mathrm{p}<0.001$; OR $=15)$, and the flooding of their homes $(p=0.045 ; \mathrm{OR}=2.81)$. Eggs of $T$. canis were detected in the feces of five of the $81 \mathrm{dogs}$ studied $(6.17 \%)$. Three of the seropositive individuals owned three dogs that eliminated the eggs of T. canis at the time of sample taking, though this result turned out to be no significant.

Eggs of Toxocara spp. were found in 21 (41.17\%) of the 51 processed dirt samples. The prevalence of these eggs in public park was $50 \%(2 / 4)$ and in homes it was $40.42 \%$ (19/47). From the 19 samples where eggs of Toxocara spp. were found, eight belonged to the surroundings of the homes of individuals with positive serology for Toxocara $(p=0.032$; OR $=4.36)$. No eggs from this parasite were found in four of the surroundings of seropositive individuals' homes. The dirt from the surroundings of three of the individuals with positive serology and egg-releasing dogs was contaminated.

\section{DISCUSSION}

The frequency of toxocariasis in a rural population of the province of Buenos Aires, Argentina, was determined 
TABLE III

Environmental and socio-cultural characteristics of 100 people from General Mansilla, Argentina. Distribution according to seroprevalence of toxocariasis

\begin{tabular}{lcrrr}
\hline & $\begin{array}{c}\text { Number of } \\
\text { people }\end{array}$ & \multicolumn{2}{c}{ Seropositives } & \\
& $\begin{array}{c}\text { examined } \\
\end{array}$ & $\mathrm{N}$ & $\%$ & $p$ \\
\hline Sanitary conditions & & & & \\
$\quad$ Good & 46 & 12 & 26.1 & 0.317 \\
$\quad$ Fair & 29 & 8 & 27.6 & \\
$\quad$ Bad & 25 & 3 & 12 & \\
Flooding in the home & & & & \\
surrounding area & & & & \\
$\quad$ Yes & 56 & 16 & 28.6 & 0.135 \\
$\quad$ No & 44 & 7 & 15.95 & \\
$\quad$ Dogs in the home & & & & \\
$\quad$ Presence & 81 & 23 & 28.4 & 0.005 \\
$\quad$ Absence & 19 & 0 & 0 & \\
\hline
\end{tabular}

Good: house made of masonry, cement floors, municipal garbage collection, running water, sewing system; Fair: house made of masonry, cement floors, no municipal garbage collection, water from home pump, and septic chamber well; Bad: house made of wood and/or tin and/or cardboard, dirt floors, garbage disposed "open-sky", water from community pump, and latrine.

in this study. Several Argentine authors have reported frequencies such as $10.6 \%$ in blood donors (Minvielle et al. 2000), 37\% in children from Resistencia, Chaco (Alonso et al. 2000), though the studied populations have both demographic and socio-cultural differences.

As regards other countries, our results are similar to those found in Nigeria (29.8\% - Ajayi et al. 2000) and Brazil (21.8\% - Campos Junior et al. 2003; 23.9\% - Anaruma Fhilo et al. 2002), though Fan et al. (2004 a,b) reported 76.6 and $46 \%$, respectively, in aborigines from Taiwan, Idawela et al. (2003) reported $43 \%$ in Sri Lanka, and Alderete et al. (2003) reported 38\% in São Paulo, Brazil. Lower values were published in North Brazil by Andrade et al. (2005) $(12.1 \%)$ and in Venezuela by García-Pedrique et al. (2004) (9.72\%).

Some reports indicate that males have a higher opportunity of getting infected by T. canis (Holland et al. 1995, Alonso et al. 2000). Contrariwise, Magnaval and Baixench (1993) indicate that females are more frequently infected than males. In this study, there was no significant differences respect the sex.

Regarding the analysis between age and frequency, no significant association was found, but it was higher in 14-year-olds or younger people, both in females and males. Similar findings have been reported by other authors in studies carried out in Taiwan (Fan et al. 2004 a), Argentina (Alonso et al. 2000), Nigeria (Ajayi et al. 2000), and Venezuela (García-Pedrique et al. 2004).

An association between eosinophilia and infection by T. canis was observed in this study, in agreement with Alonso et al. (2000) but in disagreement with Anaruna Fhilo et al. (2002) in their study carried out in Brazil. Eosinophilia was also associated with infection by $A$. lumbricoides, though only two individuals had both infections simultaneously.

The percentages of seropositivity in dog owners in this study suggest that this group shows risk of infection. However, Woodruff et al. (1978) and Ajayi et al. (2000) did not find association between dog owners and seropositivity for toxocariasis.

Those individuals owning dogs and showing positive serology had higher frequency of house flooding, a condition that would favor the evolution and survival of T. canis eggs. At the moment of the study, only five dogs turned out to eliminate the eggs of this parasite; three of them belonged to serologically positive owners with contaminated home-surrounding areas.

Taking into account the biological cycle of T. canis, the presence of dogs eliminating eggs to the environment at some point in their lives, an environment with characteristics - such as flooding - that favor the evolution and survival of eggs so that their viability is extended, we are faced with a set of variables increasing the risk of infection in this population.

The results of this study revealed a high contamination of the soil with eggs of Toxocara spp., and this would cause the infection of this population through the ingestion of contaminated dirt, specially among children whose playing habits and sites make the contact with this infection source easy (Fan et al. 2004a).

The frequency of anti-toxocara antibodies found among this rural population was not related with the sanitary condition of the people but had a strong association with eosinophilia, the presence of intestinal polyparasitism, presence of dogs in the home, soil contamination of the home-surrounding areas and of public parks, and flooding of the home-surrounding areas.

In view of the knowledge of the variables affecting the frequency of toxocariasis in this population, it is recommended that Public Health programs specially addressed to the anti-parasitic treatment of dogs are implemented. This control activity would diminish in a short term and at a low cost the environmental contamination with eggs of $T$. canis and consequent human infection.

\section{ACKNOWLEDGEMENTS}

To Laura Cipolla for the translation of the manuscript.

\section{REFERENCES}

Ajayi O, Duhlinska D, Agwale S, Njoku M 2000. Frequency of human toxocariasis in Jos, Plateau State, Nigeria. Mem Inst Oswaldo Cruz 95: 147-149.

Alderete J, Jacob C, Pastorino A, Elefant G, Castro A, Fomin A, Chiefi P 2003. Prevalence of Toxocara infection in schoolchildren from the Butanta region, São Paulo, Brazil. Mem Inst Oswaldo Cruz 98: 593-597.

Alonso J, Bojanich M, Chamorro M, Gorodner J 2000. Toxocara seroprevalence in children from a subtropical city in Argentina. Rev Inst Med Trop São Paulo 42: 235-237.

Anaruma Filho F, Cheffi P, Correa C, Camargo E, da Silveira E, Aranha J, Riveiro M 2002. Human toxocariasis: a seroepidemiological survey in the municipality of Campinas (SP), Brazil. Rev Inst Med Trop São Paulo 44: 301-305. 
Anaruma Filho F, Cheffi P, Correa C, Camargo E, da Silveira E, Arabga J 2003. Human toxocariasis: incidence among residents in the outskirts of Campinas, state of São Paulo, Brazil. Rev Inst Med Trop São Paulo 45: 293-294.

Andrade Lima Coelho R, Carvalho L, Perez E, Araki K, Takeuchi T, Ito A, Aoki T, Yamasahi H 2005. Prevalence of toxocariasis in Northeastern Brazil based on serology using recombinant Toxocara canis antigen. Am J Trop Med Hyg 72: 103-107.

Campos Júnior D, Rubinsky Elefant G, Ourique de Melo E, Gandolfi L, Abe Jacob C, Tofeti A, Pratesi R 2003. Frequency of seropositivity to Toxocara canis in children of different socioeconomic strata. Rev Soc Bras Med Trop 36: 25-27.

De Savigny D, Voller A, Woodruff A 1979. Toxocariasis: serological diagnosis by enzyme immunoassay. J Clin Pathol 32: 284-288.

Despommier D 2003. Toxocariasis: clinical, epidemiology, medical ecology, and molecular aspects. Clin Microbiol Rev 57: 265-272.

Fan C, Lan H, Hung C, Chung W, Liao C 2004a. Seroepidemiology of Toxocara canis infection among muntain aboriginal adults in Taiwan. Am J Trop Med Hyg 71: 216-221.

Fan C, Hung C, Dun W, Liao C, Du W, Su K 2004b. Seroepidemiology ot Toxocara canis infection among mountain aboriginal schoolchildren living in contaminated districts in eastern Taiwan. Trop Med Int Health 9: 1312-1318.

Gamboa M, Basualdo J, Córdoba M., Pezzani B, Minvielle M, Lahitte H 2003. Distribution of intestinal parasitoses in relation to environmental and sociocultural parameters in La Plata, Argentina. J Helminthol 77: 15-20.

Garcia-Pedrique M, Diaz-Suarez O, Estevez J, Cheng-Ng R, Araujo Fernandez M, Castellano J, Araujo J, Cabrera L 2004. Prevalence of infection by Toxocara in schoolchildren in the community of el Mojain, Zulia state, Venezuela. Invest Clin 45: 347-54.

Guerra A, Navarro C, Ladrón Guevara C 1995. Seroprevalence of toxocariasis in children and case of VLM. Eur J Epidemiol 11: 701-702.
Habluetzel A, Traldi G, Ruggieri S, Attili A, Scuppa P, Machetti R, Menghini G, Esposito F 2003. An estimation of Toxocara canis prevalence in dogs, environmental egg contamination an risk of human infection in the Marche region of Italy. Vet Parasitol 113: 243-52.

Holland C, O'Lorcain P, Taylor M, Kelly A 1995. Seroepidemiology of toxocariasis in school children. Parasitology 110: 535-545.

Idawela D, Kumarasiri P, de Wijesund M 2003. A seroepidemiological study of toxocariasis and risk factors for intection in children in Sri Lanka. Southeast Asian J Trop Med Public Health 34: 7-15.

Kozakos K 1983. Improved method for recovering ascarid and other helminth eggs from soil associated with epizootic and during survey studies. Am J Vet Res 44: 896-900.

Magnaval J, Baixench M 1993. Toxocariasis in the Midi Pyrenées region. In JW Lewis, RM Maizels (eds), Toxocara and Toxocariasis, Bristish Society for Parasitology, London, p. 63-69.

Minvielle M, Taus M, Raffo M, Ciarmela M, Basualdo J 2000. Seroprevalence of toxocariasis in blood donors of Gualeguaychú, Argentina. Trans R Soc Trop Med Hyg 94: 373375.

Radman N, Archelli S, Fonrouge R, Guardis M, Linzitto O 2000. Human Toxocarosis. Its seroprevalence in the City of La Plata. Mem Inst Oswaldo Cruz 95: 281-285.

Taranto N, Cajal S, De Marzi M, Fernandez M, Frank F, Bru A, Minvielle M, Basualdo J, Malchiodi E 2003. Clinical status and parasitic infection in a Wichi Aboriginal community in Salta, Argentina. Trans R Soc Trop Med Hyg 97: 554-558.

Thompson D, Bundy D, Cooper E, Schuantz P 1986. Epidemilogical characteristics of Toxocara canis zoonotic infection of children in a caribbean community. Bull WHO 64: 283-290.

Wolfe A, Wright I 2003. Human toxocariasis and direct contact with dogs. Vet Rec 152: 419-22.

Woodruff A, De Savigny D, Jacobs D 1978. Study of toxocaral infection in dog breeders. Br Med J 2: 1747-1748. 